\title{
Uma proposta pedagógica para o ensino das literaturas dos países de língua portuguesa na China: teoria da estética da recepção em prática
}

\author{
Xueqing $\mathrm{Li}^{1}$ \\ Programa de Pós-graduação em Estudos Literários e Interculturais,
} Universidade de Macau, Macau, China

Resumo: O presente artigo concentra-se na análise do estado da arte do ensino das literaturas dos países de língua portuguesa (PLP) na China e, também, na discussão de uma nova proposta metodológica para a aula de literatura para aprendentes chineses de português língua estrangeira (PLE). Para isso, o ponto de partida teórico será a teoria da estética da recepção e do efeito, de Hans Robert Jauss e Wolfgang Iser. O objetivo específico será justificar a importância desta e outras teorias como orientação para os professores escolherem as obras, os autores e os métodos de ensino que facilitem a compreensão dos alunos e estimulem mais interações entre a obra e os aprendentes, a fim de contribuir para o aprimoramento das práticas vigentes na aula de literatura. Por fim, esta reflexão faz-se necessária tornar a aprendizagem de literatura uma experiência valorizadora da estética como ponto de convergência da compreensão cultural, competência intercultural e competências linguísticas. ${ }^{2}$

Palavras-chave: Ensino da literatura; Língua portuguesa; Estética da recepção; PLE na China; Português para falantes de mandarim.

Title: A pedagogical proposal for teaching Portuguese-speaking countries literatures in China: theory of reception aesthetics in practice

Abstract: This paper focuses on the state-of-the-art analysis in the teaching of Portuguese language literatures in China and also on the discussion of a new methodological proposal for the literature class for Chinese learners of Portuguese as a foreign language (PLE). For this, the theoretical support will be on aesthetics of reception and aesthetics of effect, created by Hans Robert Jauss and Wolfgang Iser. The specific objective will be to justify the importance of such theory as guidance for teachers to choose works, authors and teaching methods that may facilitate students' understanding, and stimulate more interactions between literary works and learners in order to contribute to the improvement of current practices in the literature class. Finally, this reflection is also necessary to make literature learning an experience that values aesthetics as a point of convergence related to cultural understanding, intercultural competence and linguistic competence.

\footnotetext{
${ }^{1}$ Doutoranda em Estudos Literários e Interculturais (Universidade de Macau). Docente do Instituto de Negócios do Sul da China da Universidade de Estudos Estrangeiros de Cantão. Orcid: https://orcid.org/0000-0002-8365$\underline{3087}$

E-mail: lixueqing@foxmail.com

2 Este artigo foi realizado no âmbito do projeto MYRG2016-00122-FAH, "Portuguese Teaching and Image Building of the Portuguese-speaking Countries in Mainland China", financiado pela Universidade de Macau.
} 
Keywords: Literature teaching; Portuguese language; Reception aesthetics; PLE in China; Portuguese for Mandarin speakers.

\section{Introdução}

Ainda hoje se observa uma notória deficiência do ensino das literaturas dos países de língua portuguesa (PLP) na China. Em comparação com a quantidade de publicações em termos de estudos de competências linguísticas e estratégias de aprendizagem de línguas, como e por que motivo ensinar a literatura aos aprendentes chineses de português língua estrangeira (PLE) tem sido uma questão muito negligenciada e ainda são escassas as pesquisas sobre uma pedagogia para o ensino das literaturas em língua portuguesa na China (HOU, 2014, p. 56). Com o desenvolvimento dos cursos de português na China, cada vez mais livros dos países lusófonos foram traduzidos para chinês. Mesmo assim, os autores de língua portuguesa atraíram pouca atenção da crítica literária chinesa, verificando-se uma existência de publicações académicas bastante limitada, como afirma Li Qiao: “Em comparação com os trabalhos traduzidos, encontram-se poucos estudos e comentários sobre a literatura portuguesa na China"3 (2006, p. 116).

Devido à grande procura de talentos de língua portuguesa nos setores económicos e comerciais (YANG, 2018, p. 214), os aprendentes de português estão mais atentos a adquirir competências linguísticas e de tradução, não dando muita importância ao desenvolvimento da sua qualidade humanista nem à capacidade de apreciação literária. Através de uma observação dos planos curriculares dos cursos de licenciatura em português, entende-se que a disciplina de Literatura representa apenas uma pequena proporção na maioria das instituições de ensino superior, normalmente lecionada em duas horas semanais e pertencente à categoria das disciplinas opcionais. Encontra-se exclusivamente uma exceção, que é a Universidade de Pequim, onde se oferece uma variedade de disciplinas relacionadas com a literatura, incluindo não só as já existentes há muito tempo, tais como História da Literatura Portuguesa e Leituras Selecionadas, História da Literatura Brasileira e Leituras Selecionadas, mas também as que foram recentemente iniciadas, por exemplo, Tradução Literária, Poesia Portuguesa, Literatura de Viagem Portuguesa, Leituras Selecionadas de Escritores Africanos de Língua Portuguesa, e assim por diante.

A negligência da literatura no ensino de línguas estrangeiras na China começou pela ampla aplicação da pedagogia comunicativa nos anos 80 , altura em que um grande número de tópicos quotidianos foram introduzidos nos materiais didáticos, reduzindo, de maneira significativa, o uso de materiais literários no ensino de línguas estrangeiras, o que "faz com que as pessoas geralmente acreditem que a forma da linguagem literária está muito longe da

\footnotetext{
${ }^{3}$ Tradução minha de “和翻译的作品相比，我国对葡萄牙文学的研究、评论略少”。
} 
forma da comunicação diária"4 (YANG, 2002, p. 31). E o tal ato de distanciar a literatura do ensino de línguas, "em grande medida, ignora os profundos conhecimentos e habilidades que os alunos poderão adquirir ao ler os textos literários" ${ }^{5}$ (CHEN, 2001, p. 49). A partir da literatura, é possível encontrar o cruzamento de variadas culturas e verificar "a transposição das experiências interculturais dos próprios escritores para o plano literário" (LIMA, 2016, p. 24). Conforme a perspetiva de Li Xin, a literatura é classificada como a essência da ideologia e da cultura nacional, "ela pode harmonizar o temperamento, desenvolver o valor estético, aprimorar a qualidade integral do aluno e, consequentemente, aperfeiçoar as habilidades de comunicação intercultural" 6 (2019, p. 118). E isso também se verifica no trabalho de Gonçalves, que refere: "a literatura tem aspetos muito especiais para oferecer à aprendizagem de língua e de culturas, podendo constituir uma ótima forma de integrar o desenvolvimento holístico da $\mathrm{CCl}^{7}$ em aula" (2016, p. 129).

Por seu turno, Byram entende a competência comunicativa intercultural como "a habilidade de interagir com pessoas de outro país e cultura em uma língua estrangeira" 8 (BYRAM, 1997, p. 71). E essa habilidade de interação requisita o conhecimento de outra cultura, o qual está "ligado à sua competência linguística através da sua capacidade de usar a língua de maneira apropriada, e à sua compreensão de significados, valores e conotações específicos da língua que se usa" ${ }^{\prime \prime}$ (Idem). Se quisermos que os alunos comuniquem de uma maneira mais eficiente e elegante, é preciso que eles possuam uma maior consciência cultural e um nível elevado de habilidade de comunicação intercultural, de modo a poderem escolher o estilo de fala e a expressão linguística apropriados de acordo com as diferentes circunstâncias e interlocutores. Somente por meio de alguns diálogos em cenários da vida quotidiana não será concluída a formação dessas competências de comunicação intercultural.

Mesmo que para Roland Barthes a narrativa seja internacional, trans-histórica e transcultural (1971, p. 19), o texto literário não se pode livrar da sua própria cultura, sendo ele o uso estético da língua, e a língua encontra-se, obviamente, sempre impregnada de culturas nacionais. Os textos literários registam a cultura através da linguagem, e transmitem as crenças, padrões de pensamento e hábitos de vida dum determinado povo e duma determinada época, constituindo uma fonte essencial de obtenção de conhecimentos de teor cultural. Segundo Silva, a interculturalidade "propõe o diálogo entre as culturas" (2019, p. 144). E com base na teoria da estética da recepção, a leitura de obras literárias resulta de uma interação entre o texto e o leitor. Enquanto os alunos leem as obras literárias, realiza-se a comunicação entre duas línguas, e mais a fundo, entre duas culturas. Durante o processo de leitura, os alunos não

\footnotetext{
${ }^{4}$ Tradução minha de “使人们普遍认为文学语言的形式距离人们日常交往的形式太遥远”。

${ }^{5}$ Tradução minha de “在很大程度上忽视了学生阅读文学文本时可能获得的深层次的知识和技能”。

${ }^{6}$ Tradução minha de “它可以陶冶情操、培养审美观，提高学生的综合素养，进而提高跨文化能力”。

${ }^{7} \mathrm{CCl}$ - Competência comunicativa intercultural.

8 Tradução minha de "the ability to interact with people from another country and culture in a foreign language".

${ }^{9}$ Tradução minha de "linked to their language competence through their ability to use language appropriately, and their awareness of the specific meanings, values and connotations of the language they use".
} 
apenas absorvem a cultura estrangeira, mas também formam um tipo de feedback para a sua cultura nacional. Num ciclo constante de comparação e reflexão, é favorável os alunos atingirem o domínio das três dimensões da interculturalidade: "o domínio dos conhecimentos, das atitudes e das competências" (SEQUEIRA, 2016, p. 59).

Nos dias de hoje, com o aprofundamento do processo de integração global e sob a grande demanda da construção da iniciativa "Uma Faixa, Uma Rota", exigem-se cada vez mais talentos com perspetivas internacionais e habilidades de comunicação intercultural. Neste contexto, os estudos literários revestem-se de grande importância e constituem uma forma valiosa para potenciar a interculturalidade. Perante o facto de a apreciação dos textos literários dos PLP ainda não ter despertado atenção suficiente no ensino de PLE, e de os estudos literários desempenharem um papel insubstituível na formação de talentos com competências comunicativas interculturais, é urgente especificar os problemas existentes no ensino das literaturas dos PLP na China e praticar uma pedagogia mais efetiva para tentar melhorar a situação atual, uma vez que, "num contexto moderno líquido, já não é aconselhável aprender com a experiência e com estratégia que foram empregues com êxito no passado" (Idem).

Dentro das circunstâncias acima referidas, o presente trabalho centra-se na aplicação da teoria da estética da recepção e do efeito no ensino das literaturas dos PLP na China. Antes da elaboração dessa proposta metodológica para a aula de literatura para falantes de mandarim de PLE, o texto aborda a situação atual e um panorama geral do ensino das literaturas dos PLP na China, tendo por objetivo refletir sobre os problemas existentes neste âmbito. Partindo de uma visão interativa, e com suporte teórico de Hans Robert Jauss e Wolfgang Iser, espera-se que este trabalho possa trazer contribuições ao aperfeiçoamento do atual modelo de ensino praticado na aula de literaturas dos PLP, fazendo com que a apreciação literária se torne numa experiência prestigiada de interculturalidade.

\section{Problemas existentes no ensino das literaturas dos PLP}

A presente discussão sobre os problemas existentes no ensino das literaturas dos PLP vai focar-se principalmente no caso da China continental, sendo que Macau é uma outra realidade, onde se reúnem, devido a fatores históricos, vantagens linguísticas e culturais para que o território se torne num centro de ensino e investigação da língua portuguesa na China. Em comparação com as universidades do interior da China, o corpo docente de Macau é muito experiente e qualificado, incluindo não só chineses bilingues com elevada experiência, mas também uma grande percentagem de professores nativos portugueses e brasileiros. Relativamente a Hong Kong e Taiwan, como neste momento ainda não existem cursos de licenciatura em português, também estão excluídos do âmbito de discussão.

Uma das estratégias para localizar os problemas é olhar para o ensino da literatura inglesa, no caso de carência de estudos e discussões sobre o tal assunto no curso de português. Li 
Shengming, no seu texto "English literature teaching in China: flowers and thorns", destacou três problemas principais que existem no ensino da literatura inglesa, a saber: a falta de professores qualificados (1998, p. 7), a deficiência linguística por parte dos alunos (1998, p. 8) e a insuficiência dos livros didáticos (1998, p. 9), as quais parecem também constituir as maiores dificuldades que se encontram no ensino das literaturas dos PLP.

$\mathrm{Na}$ verdade, a falta de professores qualificados e a insuficiência dos livros didáticos são dois problemas graves e comuns no ensino de português na China. Quanto ao ensino das literaturas dos PLP, esses problemas até se tornam mais relevantes, "visto que a reflexão sobre o texto literário comporta também uma reflexão sobre a língua, sobre a cultura, sobre o mundo, sobre o Homem" (TELES, 2012, p. 172), e a tarefa de ensinar literatura reclama simultaneamente "a sensibilidade e a ponderação do docente" (Idem, p. 176). A maior razão que causa os problemas no ensino de português é o grande florescimento dos cursos de português na China depois de 2005. Antes desse ano, existiam apenas três universidades ${ }^{10}$ que ofereciam curso de PLE. A partir daí, com a assinatura de Acordo entre o Governo da República Portuguesa e o Governo da República Popular da China sobre Cooperação Económica (2005) e de Declaração Conjunta dos Governos de República Portuguesa e da República Popular da China sobre o Reforço de Relações Bilaterais (2005), começou a haver uma grande necessidade de talentos de português nos setores culturais, económicos e comerciais, onde a procura de tradutores e intérpretes era maior que a oferta. Verificaram-se, por conseguinte, ondas de abertura do curso de português na China. Hoje em dia, após um período de 14 anos, já se encontram 45 instituições de ensino superior com curso de português ${ }^{11}$, e prevê-se que "ainda haja mais universidades que queiram abrir o curso de licenciatura em língua portuguesa" (HU, 2018, p. 47).

De acordo com Ye Zhiliang, devido à expansão rápida do ensino de português na China, muitas universidades chinesas, ao iniciarem o curso de português, decidiram "contratar um recém-formado (licenciado ou mestrado) ou um reformado das áreas não docentes para ser o(s) seu(s) primeiro(s) professor(es) de português" (2014, p. 45). Um dos fenómenos trazidos por este aumento explosivo dos cursos de português na China é que, "em geral, o corpo docente não está muito bem formado" (HU, 2018, p. 124). A maioria dos professores bilingues é muito jovem, com a idade por volta de 30 anos, não possui experiência de docente, nem é formada em estudos literários, por isso, imagina-se a dificuldade que eles sentem no ensino da literatura. Com o objetivo de elevar o nível pedagógico de língua portuguesa em toda a China, a partir de 2006, o Instituto Politécnico de Macau realiza, durante as férias de verão, um curso de formação pedagógica, que envolve "múltiplos tópicos nas áreas de didática, elaboração de materiais, metodologia e tradutologia, atraindo muitos jovens docentes das diversas instituições universitárias da China continental" (LEI, 2012, p. 13). Mas, até ao

\footnotetext{
10 As três universidades são Universidade da Comunicação da China (1960), Universidade dos Estudos Estrangeiros de Pequim (1961) e Universidade dos Estudos Internacionais de Xangai (1977).

${ }^{11}$ Informação atualizada até a data 10 de dezembro de 2018, lançada pelo Setor Educacional da Embaixada do Brasil em Pequim.
} 
momento, esse curso de formação é realizado de forma generalizada para professores de todas as disciplinas, não se dedica à formação específica de determinada área. Sob a condição de carência dos professores qualificados em literatura e de falta de um meio efetivo para melhorar as suas capacidades pedagógicas, outro dilema é: quem é mais adequado para lecionar a aula de literatura, um professor chinês ou professor nativo de português? $\mathrm{Na}$ maioria dos casos, "os professores chineses não são tão competentes em literatura e cultura de língua portuguesa enquanto os professores portugueses não têm compreensão suficiente sobre as características e hábitos cognitivos dos estudantes chineses"12 (HOU, 2016, p. 221).

Apenas recentemente saíram três livros didáticos que se destinam ao ensino da literatura: Contos em português: ler para aprender PLE (2017), da autoria da Rosa Bizarro e Lola Geraldes Xavier, Literaturas africanas em português: uma introdução (2017), da autoria da Lola Geraldes Xavier, e Do Brasil-Colónia ao século XX: sociedade e principais tendências estéticas da literatura brasileira (2018), da autoria da Ana Saldanha. Todos os três livros dedicados às literaturas de língua portuguesa foram publicados pelo Instituto Politécnico de Macau e por professoras nativas de português. Mas a grande dificuldade para que eles sejam aplicados ao ensino das literaturas dos PLP é que foram publicados em Macau, por isso, não são comercializados na China continental, por conseguinte, ainda não é possível usar estes livros em grande escala.

Durante muitos anos, como não se podia encontrar um livro didático de literatura para orientar os jovens professores a planificar as aulas, a apresentação dos textos canónicos e o desenvolvimento das escolas literárias tornaram-se uma das únicas opções para a sala de aula. As aulas de literatura dos PLP seguiam sempre uma sistematização do passado até ao presente. No caso da literatura portuguesa, geralmente parte-se de Camões, depois aborda-se Eça de Queirós, Fernando Pessoa e José Saramago. Na literatura brasileira, segue-se normalmente a ordem de Machado de Assis, Carlos Drummond de Andrade, Jorge Amado e Clarice Lispector. Além destes, estudam-se também autores representativos de Moçambique e de Angola, como Noémia de Sousa, Luís Bernardo Honwana, Mia Couto, Pepetela e Ondjaki. Ao invés de sentir a literatura e serem trabalhadas a leitura, a interpretação e a crítica literária, o atual modelo de ensino da literatura coloca a ênfase na apresentação bibliográfica do autor, nos acontecimentos históricos e no breve resumo de uma obra literária, sem conseguir provocar o estímulo aos alunos. Acontece que na realidade, "ensinar literatura pressupõe a memorização de dados, fatos, acontecimentos, data etc." (HOU, 2014, p. 53). Para passarem no exame, os alunos aceitam passivamente a doutrinação do professor, memorizam minuciosamente as notas de aula e o estilo de escrita de cada autor, às vezes, sem terem lido a obra original do autor.

Uma das razões pela qual muitos alunos têm medo de ler a literatura original é a que já referimos antes, a deficiência na proficiência linguística por parte dos alunos, ou seja, a

\footnotetext{
${ }^{12}$ Tradução minha de “中国教师对葡语文学和文化的造诣不如葡国教师，而葡国教师对中国学生的特点以 及认知习惯了解不足”。
} 
dificuldade provocada pelas barreiras linguísticas e culturais. As habilidades linguísticas e culturais dos estudantes não são suficientes para que possam compreender o significado e a concepção dos trabalhos literários, consequentemente, "a maioria dos alunos, na verdade, não demonstra interesse pela literatura nem tenta a desenvolvê-lo sem orientação dos docentes" (Idem). Christopher Brumfit e Ronald Carter defendem que "a resposta literária apenas se cumpre de verdade quando uma leitura fluente é estabelecida"13 (1986, p. 29). Caso o aprendente não alcance, pelo menos, o nível B1 de competência linguística e cultural, é impossível realizar-se a verdadeira apreciação literária, como se mostra na pesquisa de Lima, "neste nível intermédio de proficiência linguística, os alunos deparavam-se ainda com algumas dificuldades ao nível linguístico: o vocabulário e a gramática, em concreto os tempos verbais e os adjetivos" (2016, p. 55).

Mesmo que se note uma série de problemas existentes no ensino das literaturas dos PLP, ele não atraiu muita atenção dos estudiosos. As questões que se exploram neste artigo são: como o ensino das literaturas em português pode tornar-se mais interativo? Quais as sugestões que a teoria da estética da recepção pode fornecer ao ensino da literatura?

\section{Teoria da estética da recepção e do efeito}

Diferentemente das correntes literárias anteriores, a estética da recepção enfatiza a posição central do leitor na pesquisa literária. A teoria nasceu por volta dos anos finais da década de 1960, na Universidade de Constança (Alemanha). De um modo geral, esta corrente teórica considera a leitura, a reação e a compreensão criativa dos leitores como a principal fonte de geração de significado literário e acredita que os leitores participam positivamente da criação de obras através da sua própria apreciação nas atividades literárias.

A estética da recepção enriquece o horizonte de investigação sobre as questões literárias, libertando-as de concentrações restringidas a escritores e textos, e empurrando-as para uma nova perspectiva de pesquisa. De acordo com Hans Robert Jauss, o mais importante fundador da estética da recepção, o papel de leitor é bastante ignorado nos métodos marxista e formalista, em que "compreendem o facto literário encerrado no círculo fechado de uma estética da produção e da representação" (1994, p. 8). Jauss argumenta que o valor estético de uma obra literária resulta "dos critérios da recepção, do efeito produzido pela obra e de sua fama junto à posteridade" (Idem), é esta cadeia de recepção que atribui a uma produção literária a vida, a qualidade estética e o significado histórico.

Sobre esta teoria, um conceito importante levantado por Jauss é o "horizonte de expetativas", que diz respeito à experiência estética pré-formada do leitor. Esse entendimento preexistente do leitor baseia-se na sua vida prática e na memória de leituras passadas. No

\footnotetext{
${ }^{13}$ Tradução minha de "a literary response only really starts when fluent reading has already been established".
} 
processo de leitura, o trabalho "atende, supera, decepciona ou contraria as expetativas de seu público" (JAUSS, 1994, p. 12), evoca o seu horizonte de expetativas anterior, corrigindo-o ou alterando-o, para que se forme uma nova experiência estética. Em outras palavras, o processo de leitura resulta de uma comunicação contínua entre o autor, o texto e o leitor. Quando o livro não consegue produzir nenhum efeito no seu leitor, não consegue trazer nenhuma mudança de horizonte, e não ocorre a interação mútua entre o texto e o leitor, ele pode tornar-se uma arte esquecida na estante. Em relação a este assunto, Wolfgang Iser, outro pioneiro desta vertente teórica, concorda que "o texto ficcional deve ser visto principalmente como comunicação, enquanto a leitura se apresenta em primeiro lugar como uma relação dialógica" (1996, p. 123).

Sendo a leitura uma comunicação entre o texto e o leitor, a subjetividade do leitor não pode escapar da objetividade do texto. A interpretação do leitor é particular e autónoma, mas ainda se baseia no sentido, na forma e nas críticas anteriores da obra literária. Jauss afirma que a obra "por intermédio de avisos, sinais visíveis e invisíveis, traços familiares ou indicações implícitas, predispõe seu público para recebê-la de uma maneira bastante definida" (1994, p. 11). Ao mesmo tempo, Iser também defende o papel controlador do texto em referência às interpretações arbitrárias do leitor. Na perspectiva dele, "os lugares vazios incorporam os 'relés do texto', porque articulam as perspectivas de apresentação, possibilitando a conexão dos segmentos textuais" (ISER, 1999, p. 126). No decorrer de leitura, o horizonte do leitor é desenvolvido pelos espaços vazios que se apresentam no texto, "o leitor formula várias ideias e aguarda o desenrolar do texto para verificar sua validade" (UNES, 2003, p. 762). Por um lado, - leitor mobiliza a sua imaginação para preencher as lacunas indeterminadas que se encontram no texto, por outro lado, as articulações entre os espaços em branco também restringem a imaginação do leitor a um círculo apropriado.

\section{Sugestões da estética da recepção ao ensino das literaturas dos PLP}

A introdução da teoria da estética da recepção na sala de aula de literatura não é apenas uma introdução duma teoria da crítica literária, mas também um novo paradigma para orientar o ensino das literaturas dos PLP na China.

\section{Concentração na experiência estética do aluno}

A primeira sugestão que a teoria da estética da recepção oferece é que o ensino da literatura deve concentrar-se no aluno (leitor) e que o professor deve encorajar a participação ativa dos alunos nas atividades de leitura, sendo que numa aula de literatura, "o ensino da 
literatura será um negócio árido a menos que haja respostas"14 (LONG, 1986, p. 42). De acordo com a teoria da estética da recepção, a leitura é, antes de tudo, uma comunicação, e "a obra literária é condicionada primordialmente pela relação dialógica entre literatura e leitor" (JAUSS, 1994, p. 23). Somente se praticar um ensino da literatura centralizado no seu receptor, as obras literárias ganham possibilidade de produzir efeitos nos aprendentes.

Prestar atenção às experiências pessoais e aos sentimentos estéticos dos alunos tem sido um problema que negligenciamos na prática do ensino da literatura, e isso constitui uma das principais causas do afastamento gradual entre os aprendentes e a literatura. $\mathrm{O}$ viceministro da Educação, Liu Limin, criticou que "por muito tempo, o objetivo da educação de línguas estrangeiras na China se localizava no domínio das habilidades linguísticas e do conhecimento prático, em que o valor instrumental da educação de línguas era óbvio" 15 (2009, p. 2), mas esse tipo de formação que visa cultivar talentos pragmáticos "enfraquecerá, a longo prazo, a essência da educação de línguas estrangeiras e o cuidado humanístico que a educação de línguas deve possuir"16 (Idem).

O ensino nas aulas de literatura deve chegar ao nível de uma formação humanística, sendo ele um processo de formação da personalidade, virtude e da capacidade estética dos alunos. Na sala de aula, os professores de literatura não podem permanecer no nível de interpretação linguística das obras, nem podem transmitir só teorias e críticas autoritárias. Observa-se na China que "nas aulas de literatura, sob uma designação literária, realizam-se principalmente análises sintáticas e semânticas" (HOU, 2014, p. 57). O papel do professor deve focar-se na motivação do potencial dos alunos, deixando-os interpretar os trabalhos literários de forma autónoma e intuitiva, com base nos seus próprios sentimentos, na sua própria experiência de vida e no seu próprio conhecimento cultural.

$\mathrm{Na}$ aula de literatura, os alunos obtêm um uso real e significativo das habilidades linguísticas somente por meio de atividades como analisar obras, trocar ideias e apresentar comentários. Segundo Brumfit e Carter, "o processo de leitura é um processo de criação de significado, recorrendo à integração das próprias necessidades, compreensão e expectativas com um texto escrito"17 (1986, p. 23). Portanto, o papel das obras literárias não é apenas transmitir informações sobre os enredos, mas também representar uma dedicação e participação pessoal do leitor. Conforme Gajdusek, "a exploração e a descoberta são os termos-chave"18 (1988, p. 231) para um processo interativo de leitura.

\footnotetext{
${ }^{14}$ Tradução minha de "the teaching of literature is an arid business unless there is a response".

${ }^{15}$ Tradução minha de “一直以来，我国将外语教育目标定位为掌握语言技能与实用知识，外语教育的工具 性价值倾向明显”。

${ }^{16}$ Tradução minha de “但从长远来看，却从根本上削弱了外语教育的本质和外语教育所应具有的人文关 怀”。

${ }^{17}$ Tradução minha de "the process of reading is a process of meaning-creation by integrating one's own needs, understanding, and expectations with a written text".

${ }^{18}$ Tradução minha de "exploration and discovery are the key terms".
} 


\section{Programa de ensino baseado no desenvolvimento cognitivo dos alunos}

A segunda sugestão trazida pela teoria da estética da recepção é que os conteúdos do ensino devem basear-se no desenvolvimento linguístico e na capacidade cognitiva do aluno. Conforme a discussão de Jauss sobre o conceito de "horizonte de expetativas", existe uma distância estética entre "o já conhecido da experiência estética anterior e a 'mudança de horizonte' exigida pela acolhida à nova obra" (1994, p. 12). Quanto menor a distância entre a expetativa do leitor e o trabalho a ser lido, é mais fácil para os leitores aceitarem uma obra nova, especialmente num círculo de língua e cultura diferentes. Se essa distância estética for demasiado larga, a obra poderá enfrentar "rejeição ou choque, casos isolados de aprovação, compreensão gradual ou tardia" (Idem).

Numa aula de literatura, caso a linguagem e as informações dos materiais de leitura excedam em muito a capacidade de decodificação dos alunos, o interesse deles vai diminuir pouco a pouco. Jauss defende que "a experiência primária de uma obra de arte realiza-se na orientação para o seu efeito estético, num entendimento que é prazer e o prazer é cognitivo"19 (1982, p. xxix). A leitura cognitiva é o início da apreciação, que diz respeito ao primeiro entendimento literal direto das palavras de um texto, constituindo o fundamento da leitura interpretativa. Na premissa de que a linguagem é compreensível para os alunos, eles têm vontade de conhecer a história da obra, refletir sobre as questões por baixo das palavras, concretizar, consequentemente, atividades estéticas de leitura literária. Após os alunos acumularem uma certa experiência estética de leitura, os professores podem levá-los a apreciar os romances clássicos, epopeias e rastrear as origens literárias, deixando os alunos sentirem sempre a acessibilidade das obras literárias.

Não é necessário que o ensino da literatura siga uma tradicional prática pedagógica de "desde os tempos antigos até ao presente" e "somente os cânones são respeitados". Sob a orientação do método da recepção, o maior objetivo do ensino da literatura é "levar o aluno a uma postura mais consciente com relação à literatura e à vida" ${ }^{20}$, é preciso que o professor "esteja preparado para selecionar textos referentes à realidade do aluno e que ao mesmo tempo rompam com ela" ${ }^{21}$. Em vez de iniciarem a aula de literatura com Os Lusíadas de Camões, cujos versos são difíceis, e que estão cheios de metáforas e acontecimentos históricos, os professores também podem começar pela literatura contemporânea, pelos contos e lendas, escolhendo materiais desafiadores, mas que estão dentro da capacidade de compreensão dos alunos.

O nível da dificuldade das matérias literárias deve ser decidido pelos fatores dos

\footnotetext{
${ }^{19}$ Tradução minha de "the primary experience of a work of art takes place in the orientation to its aesthetic effect, in an understanding that is pleasure, and a pleasure that is cognitive".

20 Disponível em: http://www.gestaoescolar.diaadia.pr.gov.br/arquivos/File/producoes pde/ artigo eliane maria cab ral.pdf. Acesso em: 26 ago. 2019.

${ }^{21}$ Idem.
} 
aprendentes, tais como a capacidade linguística, o conhecimento cultural, a sensibilidade cognitiva e o nível de apreciação estética. Para a disciplina de Literatura, Ye reconhece que "é necessário que os professores preparem os materiais conforme as caraterísticas dos seus discípulos, e, para isso, exige-se muita experiência de ensino e muita acumulação de materiais" (2004, p. 46), o que é muito difícil para os jovens professores. Por isso, considerando a situação atual da China, os conteúdos lecionados na aula de literatura não precisam de ser complexos nem de envolverem muitos autores, muitos géneros. É conveniente dividir a aula de literatura em tópicos diferentes, para evitar que a aula seja demasiado vasta e também para organizar de maneira mais acessível o conteúdo de ensino, tanto para os professores como para os alunos, por exemplo, os tópicos podem ser "contos em português do século XX" ou "novelas do realismo brasileiro do século XIX", entre os outros.

\section{Realização de leituras de forma eficaz}

Uma das compreensões erradas sobre a teoria da estética da recepção é que ela permite todas as maneiras de interpretação por parte dos leitores sobre as obras literárias. Tanto para Jauss como para Iser, como já referimos antes, o texto tem o papel orientador para a compreensão do leitor. Na realização da leitura, a obra "desperta a lembrança do já lido, enseja logo de início expetativas quanto a 'meio e fim', conduz o leitor a determinada postura emocional e, com tudo isso, antecipa um horizonte geral da compreensão vinculado" (JAUSS, 1994, p. 11). Dessa forma, as interpretações do leitor não são totalmente subjetivas e isso também coincide com a caraterística comunicativa da literatura, que se baseia na premissa dialógica entre a obra e o leitor.

Mesmo que a recepção evidencie uma diferença individual bastante explícita, nem todas as interpretações são razoáveis. Caso o professor incentive absolutamente todas as maneiras de interpretação, levará inevitavelmente à confusão cognitiva dos alunos sobre as obras literárias e assim, não desenvolverá verdadeiramente o nível estético dos alunos. As atividades da estética literária fundamentam-se num modo de leitura eficaz. No ensino da literatura, por um lado, os professores devem motivar os alunos a usar a sua imaginação para ter uma visão criativa, por outro lado, devem limitar os alunos a explorarem dentro das fronteiras do texto. De qualquer maneira, a apreciação literária não é uma atividade completamente subjetiva, mas uma interação dinâmica entre a obra e o leitor.

Tanto a capacidade linguística como a de percepção cultural influenciam a eficácia do ensino da literatura na sala de aula. O conhecimento prévio e a experiência cultural dos aprendentes contribuem para a percepção do texto, especialmente em atividades literárias interculturais. Não é suficiente que se proceda a uma compreensão da leitura somente no nível de palavras, mas também se deve exigir ao leitor que mobilize os conhecimentos anteriores para identificar, processar e interpretar as informações do texto. Encontra-se muitas 
vezes uma compreensão incompleta do aluno sobre o texto na prática do ensino da literatura. Por um lado, isso resulta de uma deficiência de proficiência linguística por parte dos alunos, por outro lado, também se relaciona com a falta de consciência intercultural e de conhecimentos sobre o mundo exterior.

Para cultivar talentos de português com competências comunicativas interculturais por meio do ensino da literatura, os professores devem aproveitar as obras literárias para desenvolver o horizonte intercultural dos alunos, sendo que elas dispõem da profunda marca nacional e cultural, constituem, portanto, um portador fundamental da cultura. Ao ler, por exemplo, o conto Sangue da avó, manchando a alcatifa de Mia Couto, é preciso que os alunos estejam conscientes dos conflitos entre a herança tradicional de Moçambique e a modernidade no âmbito da globalização. Somente quando "a experiência literária do leitor adentra o horizonte de expetativa de sua vida prática, pré-formando seu entendimento do mundo" (JAUSS, 1994, p. 21), realiza-se a função social da literatura e o valor essencial do ensino da literatura.

\section{Considerações finais}

O ensino da literatura merece uma atenção particular numa era em que se exigem cada vez mais talentos de português com competências comunicativas interculturais. Segundo o recém-publicado "Padrão nacional para a qualidade de ensino de línguas estrangeiras" 22, em que se regulam objetivos de formação, estrutura curricular, construção do corpo docente, condições educacionais bem como sistema de garantia da qualidade de ensino de línguas estrangeiras na China, os aprendentes dos respetivos cursos devem possuir a qualidade humanista, dominar o conhecimento das literaturas estrangeiras e ter a capacidade de apreciação literária assim como a habilidade de comunicação intercultural. Através das obras literárias, os aprendentes chineses de PLE são capazes de sentir emoções distintas e novas, permitindo, deste modo, o contato com outras culturas e estabelecimento de laços afetivos.

A aplicação da teoria da estética da recepção à aula das literaturas dos PLP é a introdução de uma ideologia interativa e com foco na participação do destinatário no ensino. A partir do princípio de prestar mais atenções aos próprios sentimentos estéticos dos alunos, a presente teoria também oferece orientações para a escolha dos materiais didáticos e para a construção do modelo eficaz de leitura no processo de ensino. É natural que os professores adotem o modo de ensino semelhante ao da sua própria aprendizagem, mas o ensino solicita sempre inovações, introdução de novas teorias e ideologias na prática. Na aula de literatura,

\footnotetext{
${ }^{22} \mathrm{Faz}$ parte do livro 普通高等学校本科专业类教学质量国家标准 [Padrão nacional para a qualidade de ensino dos cursos de licenciatura no ensino superior], que foi publicado pelo Comité Diretivo do Ministério da Educação da China para o Ensino Superior em 2018 e que compreende critérios de qualidade de ensino para todos os 587 cursos de licenciatura existentes no país.
} 
é mais significativo prestar atenção ao efeito, às experiências estéticas e mudanças de horizonte de expetativas trazidas pela obra ao aprendente do que colocar o foco de ensino na transmissão de conhecimentos literários (biografia do autor, contexto da criação e estilo de escrita etc.). Além disso, a riqueza da literatura não se limita apenas à aula, também pode ser explorada em outras disciplinas, tais como a Conversação e a Gramática, sendo que "os diálogos nas obras literárias, como se apresentam de uma maneira bem explícita as relações entre personagens e o contexto do diálogo, fornecem aos alunos um padrão e um determinado contexto do uso da língua"23 (HOU, 2016, p. 221).

Neste momento, na China, há cada vez mais obras traduzidas dos PLP, há muitas pesquisas que se dedicam ao ensino e aprendizagem do português, também há muitos professores que estudam as literaturas dos PLP, mas é lamentável que se encontrem poucos casos de estudo sobre o ensino da literatura. Com o objetivo de melhorar a situação atual do ensino da literatura na China e encontrar uma pedagogia adequada para o público determinado de aprendentes chineses, ainda há um caminho longo para percorrer e é necessária uma cooperação transfronteiriça entre os professores de português, o que é um grande desafio para os jovens professores chineses.

\section{Referências}

BARTHES, R. Introdução à análise estrutural da narrativa. In: BARTHES, R.; GREIMAS, A. J.; BREMOND, C.; ECO, U.; GRITTI, J.; MORIN, V.; METZ, C.; TODOROV, T.; GENETTE, G. (Orgs.). Análise estrutural da narrativa. Petrópolis: Vozes, 1971. p. 19-62.

BRUMFIT, C. J.; CARTER, R. A. (Orgs.). Literature and language teaching. Oxford: Oxford University Press, 1986.

BYRAM, M. Teaching and assessing intercultural communicative competence. Clevedon: Multilingual Matters, 1997.

CERVO, J. M.; ALVES, L. K. Proposta metodológica de estudo de contos sob a perspetiva da estética da recepção. Disponível em: http://www.gestaoescolar.diaadia.pr.gov.br/ arquivos/File/producoes pde/ artigo eliane maria cabral.pdf. Acesso em: 26 ago. 2019.

CHEN, H. (陈红). 外语教学中的文学观 [A literatura no ensino de língua estrangeira]. 外语与 外语教学 [Foreign Languages and Their Teaching], Dalian, n. 2, p. 49-51, 2001.

GAJDUSEK, L. Toward wider use of literature in ESL: why and how. TESOL Quarterly, Washington, D.C., v. 22, n. 2, p. 227-257, 1988. https://doi.org/10.2307/3586935

GONÇALVES, L. M. V. C. F. Uma abordagem intercultural ao ensino do português na China continental. 2016. 129 f. Tese (Doutorado em Didática de Línguas) - Programa de PósGraduação em Didática de Línguas, Universidade do Porto, Porto, 2016.

\footnotetext{
${ }^{23}$ Tradução minha de “文学作品中的对话，对人物关系和对话背景交代的很清晰，直接给予学生用语规范 和用语背景”。
} 
HOU, X. (侯㴋英). O ensino da literatura portuguesa na China: concepção e metodologia. 2014 53 f. Dissertação (Mestrado em Letras) - Programa de Pós-Graduação em Letras, Universidade de Coimbra, Coimbra, 2014.

HOU, X. (侯㴋英). 人本教育视角下葡语文学在本科葡语教学中的意义 [A importância da literatura no ensino universitário de língua portuguesa sob a perspetiva da educação humanista]. 现代交际 [Modern Communication], Changchun, n. 10, p. 220-222, 2016.

HU, J. Formação de professores de língua portuguesa no ensino superior em Tianjin/China: as práticas pedagógicas no contexto mundial da globalização. 2018. 47 f. Tese (Doutoramento em Ciências da Educação) - Programa de Pós-Graduação em Ciências da Educação, Universidade Nova de Lisboa, Lisboa, 2018.

ISER, W. O ato de leitura: uma teoria do efeito estético. Vol. 1. Tradução: Johannes Kretschmer. São Paulo: Editora 34, 1996.

ISER, W. O ato de leitura: uma teoria do efeito estético. Vol. 2. Tradução: Johannes Kretschmer. São Paulo: Editora 34, 1999.

JAUSS, H. R. Aesthetic experience and literary hermeneutics. Tradução: Michael Shaw. Minneapolis: University of Minnesota Press, 1982.

JAUSS, H. R. A história da literatura como provocação à teoria literária. Tradução: Sérgio Tellaroli. São Paulo: Ática, 1994.

LEI, H. (李向玉). Objetivo nobre e responsabilidade grande. In: FÓRUM INTERNACIONAL DE ENSINO DE LÍNGUA PORTUGUESA NA CHINA, 1., 2011, Pequim. Atas... Macau: Instituto Politécnico de Macau, 2012. p. 12-13.

LI, Q. (李峤). 葡萄牙文学在中国的译介 [Uma breve introdução à tradução da literatura portuguesa na China]. 安徽农业大学学报 (社会科学版) [Journal of Anhui Agricultural University (social science edition)], Hefei, v. 15, n. 4, p. 113-116, 2006.

LI, X. (李欣). 以文学作品为载体促进跨文化交际能力一基于接受美学视角 [Promovendo a competência comunicativa intercultural com obras literárias como portadoras - Na perspetiva da estética da recepção].学术前沿 [Frontiers], Pequim, n. 14, p. 116-119, 2019.

LIMA, S. I. Desenvolvimento da competência intercultural e literatura em aulas de PLE: relato de uma experiência em turmas de nível B. 2016. 24 f. Dissertação (Mestrado em Português Língua Segunda/Estrangeira) - Programa de Pós-Graduação em Português Língua Segunda/Estrangeira, Universidade do Porto, Porto, 2016.

LIU， L. (刘利民). 科学规划外语教育，切实服务国家战略 [Planejamento científico da educação de línguas estrangeiras, serviço efetivo à estratégia nacional]. 光明日报 [Diário Guangming], Pequim, p. 9D, 3 mar. 2009.

LONG, M. N. A feeling for language: the multiple values of teaching literature. In: BRUMFIT, C. J.; CARTER, R. A. (Orgs.). Literature and language teaching. Oxford: Oxford University Press, 1986. p. 42-59. 
SEQUEIRA, R. M. Interculturalidade crítica e globalização. In: LUNA, J. M. F. (Org.). Internacionalização do currículo: educação, interculturalidade, cidadania global. Campinas: Pontes Editores, 2016. p. 55-70.

SILVA, S. B. Transculturalidade no ensino de língua inglesa: metade de um sol amarelo na sala de aula da licenciatura. Letras \& Letras, Uberlândia, v. 35, n. especial, p. 137-154, 2019. https://doi.org/10.14393/LL63-v35nEsp2019-7

TELES, A. F. Ensinar literatura portuguesa na China. In: FÓRUM INTERNACIONAL DE ENSINO DE LÍNGUA PORTUGUESA NA CHINA, 1., 2011, Pequim. Atas... Macau: Instituto Politécnico de Macau, 2012. p. 170-177.

UNES, W. A estética da recepção - Hans Robert Jauss e Wolfgang Iser. Estudos, Goiânia, v. 30, n. 4, p. 753-766, 2003.

YANG, J. (杨俊峰). 文学在外语教学中的地位与作用 [O status e a função da literatura no ensino de língua estrangeira]. 外语与外语教学 [Foreign Languages and Their Teaching], Dalian, n. 5, p. 31-33, 2002.

YANG, J. (杨景怡). 跨文化交流视角中高校葡语教学研究 [Estudo sobre o ensino de língua portuguesa nas instituições de ensino superior sob a perspetiva da comunicação intercultural]. 科技资讯 [Science \& Technology Information], Pequim, n. 10, p. 214-215, 2018.

YE, Z. (叶志良). Algumas considerações sobre a expansão do ensino da língua portuguesa na China. In: GROSSO, M. J.; GODINHO, A. P. C. (Orgs.). O português na China: ensino e investigação. Lisboa: LIDEL, 2014. p. 42-54.

Recebido em: 21/09/2019.

Aceito em: 19/02/2020. 